\title{
Rare Case of Greenish Discolouration of Urine on Local Administration of Methylene Blue in Anal Fistula During Fistulectomy
}

\author{
Abdulrazack Farook ${ }^{1} \cdot$ Iyanar Kannan ${ }^{2} \cdot$ Dilipkumar Debarath Das $^{1}$
}

Received: 23 June 2019 / Accepted: 6 March 2020 / Published online: 30 March 2020

(C) Association of Surgeons of India 2020

\section{Dear Sir,}

A sudden change in the colour of urine during the postoperative period causes anxiety to the patient and surgeon. We came across such a case with greenish discolouration of urine after fistulectomy for fistula-in-ano. It was a case of 62year-old male, who came to the department of general surgery, of our hospital, with the complaints of fistula-in-ano. On examination, he had two fistulous tracts around the anus.

The patient underwent MRI fistulogram and taken up for surgery. Two millilitres of methylene blue was injected into the tract openings, to identify the tracts in toto. Subsequently this was followed by fistulectomy, wherein both the tracts were excised and removed. Next day of the surgery, colour of urine of the patient became green. As it was unexpected, we searched the literature to find out any case reports on greenish discolouration of urine after fistulectomy. Hence, there was no specific literature on it, we subjected the urine for laboratory analysis. The urine analysis revealed absence of bilirubin and pus cells. The urine culture was negative. The patient had no history of intake of drugs or chemicals which causes greenish discolouration of urine. Further there was no history of intake of foods which can cause greenish discolouration of urine.

However, one of the case reports, during the treatment of cutaneous fistula in hip osteomyelitis, greenish discolouration of urine was observed due to instillation of methylene blue into the fistulous tract [1]. In another case report of surgical treatment of pressure ulcer, green urine was observed after the methylene blue was used during the revision of wounds. It was suggested that the methylene blue was absorbed from the microcirculation of the wounds and subsequently excreted by the kidney [2]. It was understood that in our present case, the green colour urine was due to methylene blue dye that was injected. For the first time, we report the green discolouration of urine, due to the local administration of methylene blue in anal fistulous tract during fistulectomy and the possibility of methylene blue absorption.

\section{Compliance with Ethical Standards}

Conflict of Interest The authors declare that they have no conflict of interest.

\section{References}

1. Cvetković BR, Cvetković VR, Rosić ZV, Milenković D (2008) Late methylene blue appearance in urine after local treatment of cutaneous fistula in hip osteomyelitis as a first sign of renal failure. Acta Chir Iugosl 55(4):117-120

2. Tonseth KA, Tindholdt TT, Hokland BM, Abyholm FE (2007) Green urine after surgical treatment of pressure ulcer. Scand J Plast Recostr Surg Hand Surg 41(1):39-41

Publisher's Note Springer Nature remains neutral with regard to jurisdictional claims in published maps and institutional affiliations.

Iyanar Kannan

dr.ikannan@tagoremch.com

1 Department of General Surgery, Tagore Medical College and Hospital, Chennai 600127, India

2 Department of Microbiology, Tagore Medical College and Hospital, Rathinamangalam, Chennai 600127, India 